\title{
Health and Well-Being in Old Age: The Pertinence of a Gender Mainstreaming Approach in Research
}

\author{
Pasqualina Perrig-Chiello Sara Hutchison \\ Institute of Psychology, University of Berne, Berne, Switzerland
}

\author{
Key Words \\ Health $\cdot$ Well-being $\cdot$ Gender differences $\cdot$ Gender \\ mainstreaming
}

\begin{abstract}
Background: The demographic and societal changes of the past decades, such as longevity and improvements in public health, have created new and often very distinct realities for men and women. However, these diversities have only marginally and fragmentally been the topic of research endeavours. There is a growing awareness of the societal phenomenon 'feminization of old age', yet the topic and its psychosocial and health-related consequences have not attracted the scientific interest they deserve. Due to scientific neglects and limitations, state of the art research in the field of gender, health and ageing is still sketchy and often contradictory. Objective: In the present article, the complex pattern of roles and values that define what is thought of as 'masculine' and 'feminine' and its significant impact on health-related lifestyles will be examined. Based on current research, we try to give answers to questions such as: 'Do older women really have more physical and mental health problems than older men, or are these findings influenced by a gender bias, due to a different awareness and understanding of health and illness?' It will be shown that it is impossible to find satisfactory answers to such questions without considering the cultural and social contexts of the
\end{abstract}

individuals studied. The inclusion of gender as a social reality in the broadest sense is therefore an absolute prerequisite for gaining valid information. Conclusion: Gender has played only a marginal role in the hitherto existing geriatric and gerontological research and practice. Therefore, a gender-fair approach in research and practice is indicated, i.e. an approach that takes into account differences and commonalities of women and men and considers their differing circumstances and specific problems (gender mainstream). Gender mainstreaming entails on the one hand horizontal justice (denoting equal treatment and benefits for equal needs of men and women) and on the other hand vertical justice (indicating differential treatment and benefits for differential needs of the 2 sexes).

Copyright $\odot 2009$ S. Karger AG, Basel

\section{Introduction}

The demographic and societal changes of the past decades, such as longevity and improvements in public health, have created new and often very dissimilar realities for men and women. However, these differences have only marginally and fragmentally been the topic of empirical research endeavours. There is, for example, a generally growing awareness of the societal phenomenon 'feminization of old age', yet the topic and its psychosocial and health-related consequences have not attracted the

\section{KARGER \\ Fax +4161306 1234 \\ E-Mail karger@karger.ch}

www.karger.com (c) 2009 S. Karger AG, Basel

0304-324X/10/0562-0208\$26.00/0

Accessible online at:

www.karger.com/ger
Prof. Dr. Pasqualina Perrig-Chiello

Institute of Psychology, University of Berne

Muesmattstrasse 45

CH-3009 Bern (Switzerland)

Tel./Fax +41 3133640 35, E-Mail pasqualina.perrigchiello@psy.unibe.ch 
scientific interest they deserve [1]. It is noteworthy that even until a few decades ago, the majority of geriatric and gerontological studies were oriented towards male standards without taking into consideration gender effects $[2,3]$. Even though subsequent studies increasingly began to focus on differences between women and men, they referred mainly to the biological sex of a person rather than to the gender. Due to these scientific neglects and limitations, state of the art research in the field of gender, health and ageing is sketchy and often enough contradictory $[4,5]$. The reasons for the higher life expectancy of women are as yet unclear, as are the reasons for their higher rate of morbidity and health complaints. In the present article, the complex pattern of roles and values that define what is thought of as 'masculine' and 'feminine' and its significant impact on health-related lifestyles will be examined. Evidence from empirical findings of various longitudinal studies on ageing suggests that a well-balanced gender role identity such as androgyny could be a fundamental prerequisite for successful ageing of men and women. The conclusion strongly advocates a gender mainstreaming approach in research and practice.

\section{Differences in Life Expectancy, Health and Well-Being in Men and Women}

The universal phenomenon of a 'feminization of society' with increasing age is mainly due to women's longer life expectancy (in Switzerland, women's life expectancy is 84.2 years, while for men it is 79.4 years). Even though there is - as of yet - no conclusive explanation for this difference, one can assume that it is a multicausal phenomenon. A review of the current literature shows that the women's advantaged mortality profile can be explained by biological, social structural and behavioural factors [6]. From a biological perspective, there is evidence that women benefit from some protection against mortality. Studies suggest that estrogen helps protect women against heart disease by reducing circulatory levels of harmful cholesterol, whereas testosterone increases low-density lipoprotein [7]. In addition, women have stronger immune systems, in part because testosterone causes immunosuppression [8]. Furthermore, from a genetic perspective, women seem to have an advantage due to the presence of two X chromosomes [9]. Despite this evidence, biological factors alone cannot explain gender differences in mortality, especially since this relationship differs significantly over time and across cultures [6].
Contemporary research has increasingly begun to focus on social, structural and behavioural factors in attempting to explain the gender gap in life expectancy. It has been estimated that the actual contribution of biological factors to the significantly higher life expectancy of women is approximately 1-2 years [10]. Research has shown that gender-typical risk-avoidance behaviour plays a central role in the explanation of women's longer life expectancy. It is in accordance with traditional role expectations for women to avoid high-risk behaviour. Men are more exposed to aggressive environments and also more actively seek them out than women (be it in regard to workplace or leisure). Additionally, men are also more inclined to revert to openly aggressive problem-solving strategies that may prove fatal (conflict, war or suicide). These behavioural patterns can already be observed in early childhood and continue into old age. Analogously, women tend to show pronounced illness-avoidance behaviour. In general, women avoid hard drugs, heavy drinking and smoking, and risky sexual behaviour - not least due to their socialization. Men, in comparison, are independently of their age generally much less health conscious [11]. They sleep on average less than $6 \mathrm{~h}$ per night, tend not to have breakfast, are more likely to be overweight, eat a less varied diet, and are less informed about the impact of nutrition on health. Women also differ from men with regard to a higher intake of vitamins and supplements, and they tend to have better compliance with their doctor's medical advice. All in all, it can be said that women invest more time, money and other resources in their health than their male counterparts [5, 12]. The question of whether this gendered behaviour actually arises from gender-specific socialization or if it arises from the biology of sex is a controversial topic [3]. On the one hand, it has been argued that the behavioural differences between men and women are to a large extent laid down in their genome, e.g. since women give birth to children and also are responsible for their later upbringing, their cautiousness would help to propagate their genes [e.g. 13]. On the other hand, from a social science perspective, the salience of social role and related social status characteristics has been stressed in accounting for variation in health- and illness-related behaviours $[2,14]$. In our view, and taking into account the interconnectedness of the biological and the social factors, it might prove pragmatic to consider that gender encompasses both sex differences and the social constructs that give rise to gender differences [3].

Paradoxically, women have - despite their higher investment in health - an increased rate of morbidity al- 
ready starting in their middle years. They also have higher rates of physical complaints, anxiety and depression. The lifetime probability of developing a depressive episode is more than twice as high in women than in men (about 26 vs. 12\%). The higher rates of depression in women can first be observed in early adulthood and reach a peak in middle age, before dropping in the post-menopausal phase $[15,16]$. Empirical evidence has shown that women have a two-fold risk in comparison to men to be in the group with the highest functional disability in activities of daily living. Women suffer mainly from nonterminal illnesses that have a negative impact on everyday functioning [17]. Not only do old women in comparison with old men have a higher risk of accidents, falls and reduced functional autonomy, they also have a higher rate of dependency on psychotropic drugs, especially benzodiazepines $[12,18]$. Alcohol abuse is the only exception, with men being affected more often than women. In regard to the prevalence of Alzheimer's disease, it is again women who suffer from higher rates (the question of whether they also have higher incidence rates is still a controversial issue). This results in women constituting the majority of elderly in need of care. For this need to be met, women depend more than men on institutionalized care. They live more often in nursing homes (8 out of 10 inhabitants are female) and have a longer duration of hospital stays. Men, however, can usually rely on informal help and care [12].

\section{Gendered Lives and Roles as Main Explanations for the Differences}

The explanations for the different physical and mental health outcomes of men and women are as manifold as those for the differences in life expectancy. One explanation for the higher rates in lifetime prevalence of different diseases in women is the fact that their longer life expectancy is associated with an increased amount of risk factors, i.e. their increased multimorbidity is a direct consequence of their higher age. The 'supplementary' years of women concern the age over 80 years, an age that is known to be the beginning of increased vulnerability (e.g. the incidence of dementia increases remarkably after age 80 years). According to this explanation, women are not more ill because of their sex per se, but to a significant degree also because of their higher life expectancy. Furthermore, the higher life expectancy of women is also associated with a higher probability of negative life events, such as widowhood or the loss of loved ones [2].
A further explanation is the differential reporting of health and well-being in men and women [1]. As research on women's health has been able to show over the past years, the gender-associated rates of morbidity and complaints described here do not reflect 'true' prevalences. A closer look reveals that most of these 'facts' actually turn out to be artefacts. For example, it has been shown that a reporting bias can distort data on health and gender, as women tend to have a more holistic understanding of health, while men define health through performance and efficiency and tend to deny and underreport negative feelings [19]. This difference between men and women has a direct impact on medical treatment, and an indirect one on health costs. Somatic illnesses are more frequently diagnosed in men than in women, whereas for psychosomatic illnesses the pattern is reversed. This, of course, has an influence on the prescription of drugs - there is an overmedication of women (especially older women) regarding psychotropic drugs and especially tranquilizers; $70 \%$ of all tranquilizers are prescribed to women [20].

The reporting bias described here mirrors the very specific gender role identities men and women still exhibit. Gender role identity is socially construed. Traditionally, instrumental or agentic behaviour (i.e. the ability to actively shape one's life, be assertive, and pursue one's goals) has been associated with being male, and expressive or communal behaviour has been associated with being female [21]. In our society, the socialization of men still emphasizes instrumental abilities such as goal orientation, assertiveness, action orientation and dominance - incidentally the criteria by which psychiatry and psychology define positive mental health. Women's socialization, however, stresses expressive traits like empathy, emotionality, helpfulness and sensitivity - attributes which are associated with higher vulnerability in psychology and psychiatry. As we know from research, expressivity has been associated with higher rates of morbidity in men and women [22]. However, expressivity can also been interpreted as an asset. In general, women tend to have better social networks than men, and can therefore rely on more social support in difficult times. Women are more likely to confide in others, are more empathetic, and they are more receptive to offers of help. For men, the opposite is often the case. High instrumentality ('masculinity') may result in men choosing radical and dysfunctional coping strategies (such as excessive drinking or even actual suicide) in case of a severe loss or health problem [23]. This comes especially to bear in old age, when in addition to the increased general vulnerability there are no more moderating roles like the role as em- 
ployee and there is a widespread lack of social networks. The exponentially rising suicide rates of men older than 70 serve to illustrate this point. While the suicide rates of women (deaths by suicide per 100,000 inhabitants in Switzerland in 2007) show only a slight increase from 23 suicides at age 65-84 years to 41 at age 85 and over, the suicide rates of men rise from 53 at age 65-84 years to 140 at age 85 and over [24].

Such observations have led some researchers to consider whether masculinity could actually be hazardous for one's health, a hypothesis that was tested by Lippa et al. [25]. They examined how masculinity - as assessed in a sample of 654 men and 210 women from the famous Terman's longitudinal study at age 30 years (1940) - was related to mortality 60 years later (2000). Masculinity measures included gender diagnosticity scores, measuring the male or female typicality of occupational preferences and masculinity-femininity scores from the Strong Vocational Interest Blank. The results suggest that higher rates of masculinity, in males and females, were associated with higher mortality rates at any given age. This effect remained significant even when health behaviour and personality factors were controlled for [25]. Taken together, we can conclude that an inflexible and tenacious commitment to either female or male roles is detrimental to health and well-being.

\section{Androgyny - A Fundamental Prerequisite for Successful Ageing?}

Evidence points to the possibility that a substantial amount of the observed socialization-based gender differences may reflect cohort effects. Results from the Basel Longitudinal Study of Ageing [26] can be interpreted in this direction. In this prospective study, an initial sample of 6,000 persons (workers and employees of chemical industries in Basel) was followed over 40 years. Of the 3,768 persons who were still alive, 848 persons were randomly selected and invited to participate in the study (this restriction was made due to the complex and expensive design of the study). A total of 442 persons aged 65-94 years (312 males, 132 females, mean age: 75 years) agreed to participate and were tested in 1993. This study is interesting insofar as the women of this sample differ from traditional women samples in ageing studies. All of them were previously employed, holding multiple roles for many years. According to the results, in old age these women did not differ significantly from their male counterparts with regard to objective and subjective health, psychological well-being and functional autonomy. They also did not differ from the men with regard to healthrelated behaviour; they had neither a higher consumption of medications, nor did they have a higher rate of medical consultations. This stands in clear contrast to the findings usually reported in literature. One reason for the results of the Basel study could be that these women had to develop certain instrumental attributes (task-focussed thinking, self-confidence, assertiveness - all abilities that are decisive in work and interpersonal relationships) to hold their ground in a male-dominated environment (chemical industry) over the decades of their employment. The non-traditional gender role orientation of these women thus combined the strength of both gender roles: a social focus (reciprocally supportive relationships and a balance between interests of self and others) and active coping strategies.

It has indeed been shown in several studies that individuals who score high on both instrumental and expressive traits report better subjective health and show better health-related behaviour than other individuals [27-29]. Furthermore, there is empirical evidence that mental health is best achieved by maintaining a balance between masculine and feminine qualities. In literature, a wellbalanced identity combining the virtues of both genders (feminine and masculine traits) has been referred to as androgyny [30]. There is increasing empirical evidence from gerontological research that androgyny could be a core competence for successful ageing. One example comes from the Bonn Longitudinal Study on Ageing reported by Fooken and Rott [31]. The authors looked at gender-specific patterns of health aspects and of central 'commitments' (i.e. internal resources) at the onset of old age as predictors of advanced longevity. It was assumed that cross-gender attributes have a positive impact on life expectancy. Accordingly, theoretical conceptions were tested via structural equation modeling using empirical data of 202 men and women who had lived to a minimum age of 70 years and whose final age at death is known. Indeed, 'interpersonal commitment' (empathetic and value-oriented social commitment, a rather typical feature of psychological femininity) proved to be a substantial predictor for male longevity, whereas 'transpersonal commitment' (purposeful investment in social relations, a rather typical feature of psychological masculinity) played the same role for women. These results have been interpreted as a way of 'androgynous competence', which turns out to be a successful life approach at the beginning of old age in order to become very old. 
These results emphasize once more that biological sex by itself is not sufficient to explain certain differences between men and women. The necessity of including sociobiographical variables in empirical research cannot be disregarded any longer.

\section{Conclusions and Practical Implications}

Even though biological differences are undoubtedly relevant for explaining the differences in life expectancy and health of men and women, too much emphasis has been placed on them in the past. The sociocultural context has a much stronger influence on the life expectancy and health biographies of men and women. Gender-based inequalities that have developed over the lifespan cumulate in old age and determine differences in health status and well-being. As most illnesses associated with old age are chronic and determined considerably by social factors, lifestyles and health behaviours, there is substantial potential for preventive measures. Gender has played only a marginal role in the hitherto existing geriatric and gerontological research and practice. Therefore, a gender-fair approach in research and practice would be indicated, i.e. an approach that takes into account differences and commonalities of women and men and considers their differing circumstances and specific problems (gender mainstream).
Gender mainstreaming entails on the one hand horizontal justice (denoting equal treatment and benefits for equal needs of men and women) and in addition vertical justice (indicating differential treatment and benefits for differential needs of the 2 sexes). Differential treatment of the sexes could for example comprise the following:

- For women: investment in a socialization that emphasizes self-efficacy and instrumentality, and questioning of external norms, additionally, networks against loneliness, easing of the burden of caretaking, and preventive measures against dementia, falls and fractures.

- For men: prevention of unhealthy lifestyles at an early age, encouraging self-disclosure, claiming of professional (medical, psychological) help at an early stage, gender-fair assessment of depression.

From everything mentioned here, it becomes evident that gender mainstreaming requires an inter- and transdisciplinary approach. Gender is not only a neglected, but also a highly complex construct that cannot be allotted to one single discipline. In view of the complexity of the issue, it is frustrating to see that the majority of scientific work carried out so far was mainly mono-disciplinary, but also to a large extent descriptive and rather theory poor. As a consequence, we are faced with the impossibility of grasping the complex underlying causes and mechanisms of gender, health and ageing. However, in order to enable optimal age- and gender-appropriate assessment, prevention and intervention, there is a need for in-depth multi-causal innovative approaches.

\section{References}

1 Perrig-Chiello P: Alter, Gesundheit und Geschlecht (age, health, and gender). Lead Opin Neurol Psychiatr 2007;3:24-26.

2 Arber S, Davidson K, Ginn J: Gender and Ageing. Changing Roles and Relationships. Philadelphia, Open University Press, 2003.

3 Philips SP: Defining and measuring gender: a social determinant of health whose time has come. Int J Equity Health 2005;4:11.

4 Backes GM, Lasch V, Reimann K: Gender, Health and Ageing. Wiesbaden, VS Verlag für Sozialwissenschaften, 2006.

5 Perrig-Chiello P: Frauen im Alter: Vorurteile und Fakten (women in old age: prejudices and facts). Z Interdisziplinäre Frauenforschung 2005;16:199-219.

6 Gorman GK, Read JG: Why men die younger than women. Geriatrics Aging 2007;10:182191.

7 Newman AB, Brach JS: Gender gap in longevity and disability in older persons. Epidemiol Rev 2001;23:343-350.
8 Owens IPF: Ecology and evolution: sex differences in mortality rate. Science 2002;297: 2008-2009.

9 Shephard R: Constitution or environment? in Shephard R (ed): Gender, Physical Activity, and Aging. Boca Raton, CRC Press, 2002, pp 151-174.

10 Luy M: Die geschlechtsspezifischen Sterblichkeitsunterschiede - Zeit für eine Zwischenbilanz (gender-specific differences in mortality - time to take stock). Z Gerontol Geriatr 2002;35:412-429.

11 Craig R, Shelton N: Healthy lifestyles, knowledge attitudes and behaviour. Leeds, National Center for Social Research, 2008.

12 Swiss Federal Office of Health: Fokusbericht Gender und Gesundheit; in Schweizerische Eidgenossenschaft BfG. Bern, Swiss Federal Office of Health, 2008.

13 Olshansky SJ, Carnes BA, Butler R: If humans were built to last. Sci Am 2001;284:5055.
14 Arber S, Cooper H: Gender differences in health in later life: the new paradox? Soc Sci Med 1999;48:61-76.

15 Burt VK, Hendrick VC: Clinical manual of women's mental health. Arlington, American Psychiatric, 2005.

16 Nolen-Hoeksema S: Gender differences in depression; in Gotlib IH, Hammen CL (eds): Handbook of Depression. New York, Guilford, 2002, pp 492-509.

17 Strauss E, Agüero-Torres H, Kareholt I, Winblad B, Fratiglioni L: Women are more disabled in basic activities of daily living than men only in very advanced ages: a study on disability, morbidity, and mortality from the Kungsholmen project. J Clin Epidemiol 2003;56:669-677.

18 Simoni-Wastila L: The use of abusable prescription drugs: the role of gender. J Womens Health Gend Based Med 2000;9:289-297. 
19 Oksuzyan A, Juel K, Vaupel JW, Christensen $\mathrm{K}$ : Men: good health and high mortality; sex differences in health and aging. Aging Clin Exp Res 2008;20:91-102.

20 Swiss Federal Office of Statistics: Beruhigungsmittelkonsum (consumption of tranquilizers). www.bfs.admin.ch/bfs/portal/ de/index/infothek/lexikon/bienvenue login/blank/zugang_lexikon.Document.118180.xls (accessed 11 March, 2009).

21 Spence J, Buckner C: Instrumental and expressive traits, trait stereotypes, and sexist attitudes: What do they signify? Psychol Women Q 2000;24:44-63.

22 Lippa RA: Gender, Nature, and Nurture. Mahwah, Lawrence Erlbaum Associates, 2002.

23 Kivimäki M, Vahtera J, Elovainio M, Lillrank B, Kevin MV: Death or illness of a family member, violence, interpersonal conflict, and financial difficulties as predictors of sickness absence: longitudinal cohort study on psychological and behavioral links. Psychosom Med 2002;64:817-825.
24 Swiss Federal Office of Statistics: Sterbefälle und Sterbeziffern wichtiger Todesursachen, nach Alter und Geschlecht (deaths and mortality rates according to causes, age, and sex). www.bfs.admin.ch/bfs/portal/de/index/ themen/14/02/04/key/01.html (accessed 1 April, 2009).

25 Lippa RA, Martin LR, Friedman HS: Gender-related individual differences and mortality in the Terman Longitudinal Study: is masculinity hazardous to your health? Pers Soc Psychol Bull 2000;26:1560-1570.

26 Perrig-Chiello P, Staehelin HB: Frauen und Gesundheit im Alter: Objektive und subjektive Gesundheit und Gesundheitsverhalten von pensionierten Arbeiterinnen und Angestellten (Women and health in old age: objective and subjective health and health behaviour of retired female workers and employees). Z Gerontopsychol Psychiatr 1996;9: 195-205.

27 Baffi CR, Redican KJ, Sefchick MK, Impara JC: Gender role identity, gender role stress, and health behaviors: an exploratory study of selected college males. Health Values 1991; 15:9-18.
28 Evans RI, Turner SH, Ghee KL, Getz JG: Is androgynous sex role related to cigarette smoking in adolescents? J Appl Soc Psychol 1990;20:494-505.

29 Shifren K, Bauserman RL: The relationship between instrumental and expressive traits, health behaviors, and perceived physical health. Sex Roles 1996;34:841-864.

30 Woodhill BM, Samuels CA: Positive and negative androgyny and their relationship with psychological health and well-being. Sex Roles 2003;48:555-565.

31 Fooken I, Rott C: Geschlechtstypische Wege in die Langlebigkeit? Zum differentiellen Stellenwert von Ressourcen, Risiken und Resilienz bei über 70 jährigen Männern und Frauen (Gender-specific ways to a long life? About the differential significance of resources, risks, and resilience in men and women older than 70). Z Med Psychol 2000; 9:27-36. 